\title{
HEAT TRANSFER AND PRESSURE DROP CHARACTERISTICS OF ANGLED SPIRALLING TAPE INSERTS IN A HEAT EXCHANGER ANNULUS
}

\author{
H. Coetzee, L Liebenberg, SA Oerder, H vd Vyver, and J.P. Meyer* \\ *Author for correspondence \\ Department of Mechanical and Manufacturing Engineering, \\ Rand Afrikaans University, \\ P.O. Box 524, Auckland Park, 2006, \\ South Africa, \\ E-mail:.jpm@ing1.rau.ac.za
}

\begin{abstract}
The purpose of this paper was to determine the single phase heat transfer and pressure drop characteristics of an angled spiralling tape inserted into the annulus of a tube-in-tube heat exchanger. Experimental measurements were taken on four setups: a normal tube-in-tube heat exchanger used as a reference and three heat exchangers with different angled spiralling tape inserts. From the results correlations were developed that can be used to predict the heat transfer and pressure drop characteristics. It was concluded that the angled spiralling tape inserts resulted in an increase in the heat transfer and pressure drop characteristics as can be expected.
\end{abstract}

\section{INTRODUCTION}

Heat transfer enhancement is the process of improving the performance of a heat transfer system. It generally means increasing the heat transfer coefficient. Bergles [1] gives a comprehensive survey on heat transfer enhancement. According to him heat transfer enhancement has been studied since the first documented study of heat transfer. For example, Newton suggested in 1701 "... not in a calm air, but in a wind that blew uniformly upon it...", which was an effective way of increasing the convective heat transfer. Bergles [1] states that Joule was the first to use second-generation heat transfer in 1891, when he reported significant improvement in the overall heat transfer coefficient for in-tube condensation of steam, when a helically coiled wire was inserted into the cooling jacket. The only second-generation enhancement device that was used in the 1800 s with any regularity was the twisted tape insert. In 1896 Whitham, who inserted twisted tape inserts into the tubes of a fire-tube boiler, reported an increase of up to $18 \%$ in the boiler efficiency.

In many cases heat transfer enhancement in tubes may be supplemented by heat transfer augmentation on the outside wall of tubes, as for tube-in-tube heat exchangers. An application is in vapour compression hot-water heat pumps where an axially coiled tube-in-tube heat exchanger [2] is used for heating water in the condenser of a hot-water heat pump. The condensing refrigerant may typically flow in the inner tube and the water to be heated in a counterflow direction in the annulus. Heat transfer enhancement on the inner or outer tube decreases the temperature difference between the condensing refrigerant and water to be heated, which is an advantage as higher hot temperatures may be delivered.

In a review paper by Liebenberg et al. [3] it is shown that a lot of work has been done in heat transfer enhancement on the inner wall of tubes. However, in the case of water heating with refrigerants flowing in the inside of a tube and water through the annulus, heat transfer enhancement on the outside wall is important. The heat transfer from the refrigerant to the water through the tube is influenced by three components, namely: the thermal convection resistance of the condensing refrigerant on the inside of the inner tube $\left(1 / h_{1} A_{i}\right)$, the conduction resistance of the tube wall $\left(\ln \left(r_{d} / r_{i}\right) /(2 \pi k L)\right)$ and the convection resistance $\left(1 / h_{o} A_{o}\right)$ of the water in the annulus.

The tube wall is thin and has a high thermal conductivity $(k)$. The result is that the wall's thermal resistance is negligibly small in comparison with the two convection resistance terms. The heat transfer coefficient of condensing refrigerant $\left(h_{i}\right)$ is usually relatively large in comparison with the convection coefficient $\left(h_{o}\right)$ of the water in the annulus. Therefore, the thermal resistance is the highest on the annulus side of the wall and that is the reason why heat transfer enhancement on the outside wall of the inner tube can make an important contribution to deliver higher hot-water temperatures.

Previous work to improve the heat transfer coefficient in annuli was done by Van der Vyver and Meyer [4]. They used a round tube inside a twisted square tube. The function of the twisted square tube was to enhance a rotation component in the annulus, which increased the heat transfer coefficient by up to $50 \%$. At the same time the friction factor increased by up to 
$50 \%$. At the same time the friction factor increased by up to 9 per cent.

Another method used by Herman and Meyer [5] was to use a spiralling tube inside the annulus of a tube-in-tube heat exchanger. Three tubes were thus used. Except for the inner and outer tube, the third tube was spiralled in the annulus of the other two and also formed a flow passage. The mechanism of heat transfer enhancement was thus also to cause swirl movement of the flow in the annulus. The heat transfer enhancement' improved the heat transfer coefficient in the annulus by an average of 600 per cent and the friction factor by 84 per cent.

A third method that was investigated by Coetzee et al. [6] and Dirker et al. [7], which is simpler, is the use of thin wires in the annulus that are spiralled around the inner tube. Several studies $[8,9]$ were done to determine the spiral angle and the optimum wire thickness. Recently Krüger [10] investigated the mechanism of the heat transfer enhancement by making use of computational fluid dynamics and found that there is a strong correlation between the wire angle and the rotational velocity in the annulus. She concluded that the heat transfer enhancement is primarily caused by the flow rotation and not by an increase in turbulence of the flow over the wires.

Most of the methods of enhanced heat transfer use the same mechanism to enhance heat transfer, and that is to force the flow in the annulus to rotate. Bergles [1] has found that devices that induce swirl flow and turbulence in the flowing fluid are particularly attractive enhancement techniques for forced convective systems. Another method that makes use of this principle was patented recently by Meyer and Coetzee [11]. An angled spiralling tape as shown in Fig. 1 is used in the annulus to induce swirl. This method of heat transfer enhancement was specifically developed for hot-water heating in heat pumps, although many more applications exist.

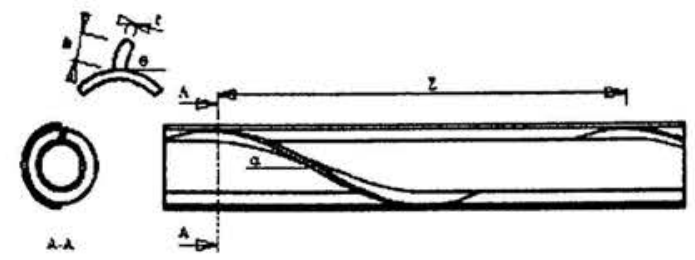

Figure 1: Schematic Representation of an Angled Spiralling Tape Heat Exchanger.

In the case of water heating with a heat pump for which the heat transfer enhancement technique was developed, the refrigerant will flow in the inner t:be and the water in the counterflow direction in the annulus. The purpose of this paper is to determine experimentally the heat transfer and pressure drop characteristics of single phase water in the annulus of the angled spiralling tape heat exchanger and to develop correlations that describe each of these characteristics.

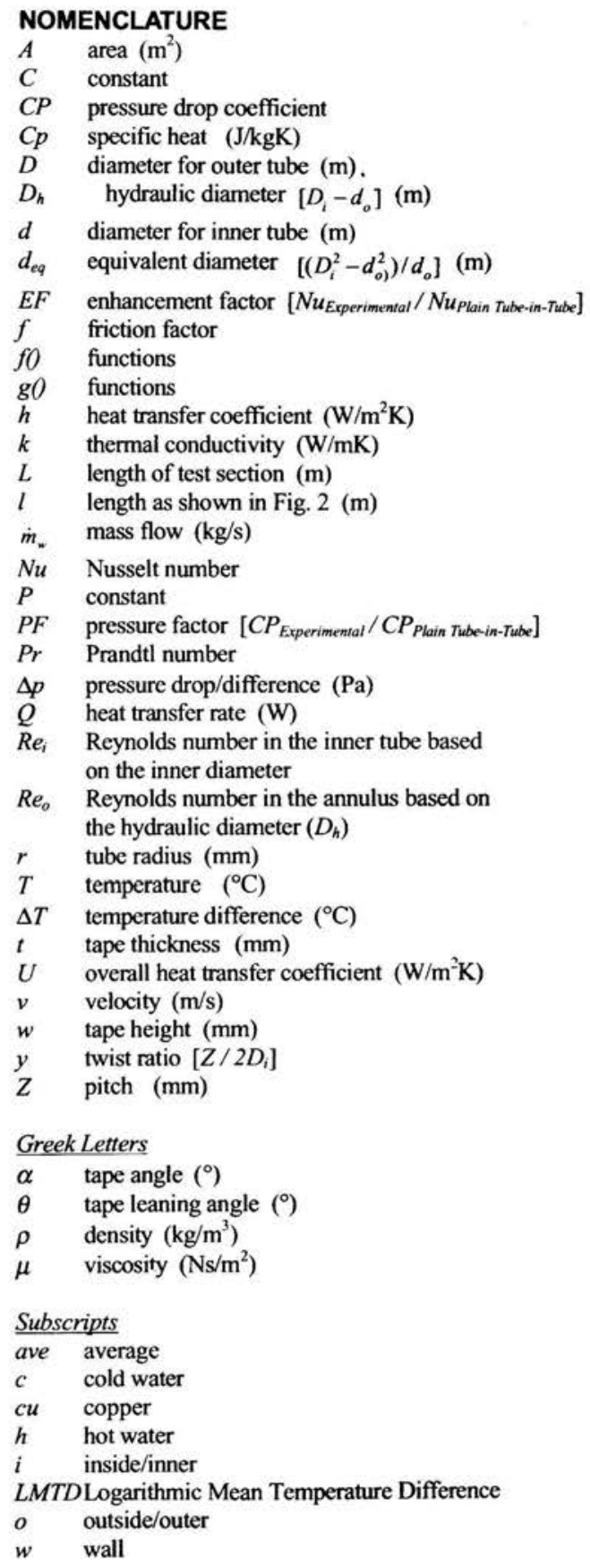




\section{EXPERIMENTAL METHOD}

Facility

The experimental set-up consisted of a closed system, using both a hot-water and cold-water cycle. The heat exchanger was tested with water in both the inner tube and annulus, as it is not necessary to use refrigerant in the inner tube for the determination of the annulus characteristics. Both the hot-water and cold-water systems consisted of the following: the test section (Fig. 2), a reservoir, pump, two valves, a positive displacement meter, a flow control valve and a rotameter. The cold-water tank was connected to a chiller to cool the water, while the hot-water tank had an electric resistance heater connected to heat the water.

The tube-in-tube heat exchanger consisted of two concentric, hard-drawn, copper tubes, used primarily in the refrigeration industry. The outer tube had an outside diameter of $15.88 \mathrm{~mm}$ and an inside diameter of $14.26 \mathrm{~mm}$. The inner tube had an outside diameter of $9.53 \mathrm{~mm}$ and an inside diameter of $8.11 \mathrm{~mm}$. The total length of the heat exchange areas was $2.97 \mathrm{~m}$. All the spiralling tape inserts were constructed from copper plate with a thickness of $1 \mathrm{~mm}$. The tape inserts were cut to a height of $2.2 \mathrm{~mm}$ to give a bit of clearance between the annulus inner wall and the tape inserts. The first heat exchanger constructed had no spiralling tape inserts, while the other three heat exchangers had tape inserts with a pitch ( $Z$ in Fig. 1) of $25 \mathrm{~mm}, 62 \mathrm{~mm}$ and $100 \mathrm{~mm}$ respectively. These pitches correspond to twist ratios $(y)$ of $0.731,1.799$ and 2.878 respectively.

Foam insulation with a thickness of $\pm 10 \mathrm{~mm}$ was used to minimize heat losses to the atmosphere. Hot water flowed in the annulus of the heat exchanger, while cold water flowed in an opposite direction in the inner tube. Also shown in Fig. 2 is a schematic representation of the temperature and pressure drop attachment points of the test section through which the water flows. Two mercury manometers were connected to the experimental set-up to measure the pressure drop over the annulus and inner tube. The distance over which the pressure drop was measured for the inner tube $\left(l_{i}\right)$ was $\pm 3.11 \mathrm{~m}$, while for the annulus $\left(l_{o}\right)$ the distance was $\pm 2.87 \mathrm{~m}$.

Four calibrated K-Type thermocouples $\left( \pm 0.1^{\circ} \mathrm{C}\right.$ accuracy) were installed on the surface of the hot- and cold-water, inlet and outlet points. The thermocouples were attached tightly onto the tube surfaces with insulation tape. Insulation was placed over the thermocouples to minimize heat transfer to the atmosphere.

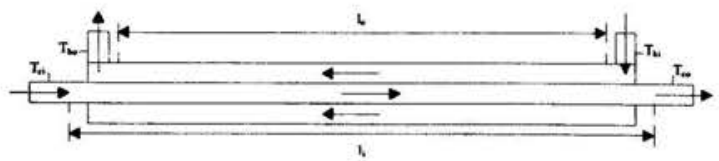

Figure 2: Experimental Set-up of Tube-in-Tube Heat Exchanger.
The flow through the heat exchanger was calculated by means of two normal positive displacement meters $( \pm 2 \%$ inaccuracy) installed at the hot- and cold-water outlets. Using a stopwatch and the amount of water that had flowed through the system over the given time, the mass flow could be determined accurately. Rotameters ( $\pm 4 \%$ inaccuracy at full scale) were used for setting the flow to different flow rates. As the accuracy of the rotameters was not as high as with measuring flow with the positive displacement meters, the rotameters werc only used for adjusting the flow to approximate predetermined values. The rotameters were also used to confirm the calculations from the positive displacement meters.

\section{Experimental Procedure and Data Reduction \\ Heat Transfer}

To obtain a reference base for comparison purposes the plain tube-in-tube heat exchanger was considered first. The heat transfer through both the inner tube and annulus was determined from inlet and outlet temperature measurements and mass flows $\left(Q=\dot{m}_{w} C p \Delta T\right)$. The average value $\left(Q_{a v e}\right)$ between the annulus heat transfer and inner tube heat transfer was considered as the correct value. The energy balance error was determined by comparing the annulus and inner tube heat transfer to this value, and resulted in errors below $5 \%$.

With this heat transfer value the overall heat transfer coefficient can be determined from Eq. (1). The logarithmic mean temperature difference can bc determined from the temperature measurements.

$$
Q_{\text {ave }}=U_{o} A_{o} T_{L M T D}
$$

where

$$
\frac{1}{U_{o} A_{o}}=\frac{1}{A_{i} h_{i}}+\frac{\ln \left(d_{o} / d_{i}\right)}{2 \pi k_{c u} L}+\frac{1}{A_{o} h_{o}}
$$

The two heat transfer coefficients in Eq. (2) are not known and can be determined with Wilson plot type methods. The modified Wilson plot technique described by Briggs and Young [12] was used. The Sieder-Tate equation [13] was used for both the inside heat transfer coefficient (Eq. (3)) and the outside heat transfer coefficient (Eq. (4)).

Three sets of experiments were conducted where the Reynolds number in the inner tube was increased from 3000 upwards, while the Reynolds number in the annulus was held

$$
\begin{aligned}
& N u_{i}=\frac{h_{i} d_{i}}{k_{i}}=C_{i} \operatorname{Re}_{i}^{0.8} \operatorname{Pr}_{i}^{0.333}\left(\frac{\mu}{\mu_{w}}\right)_{i}^{0.14} \\
& N u_{o}=\frac{h_{o} d_{\text {eq }}}{k_{o}}=C_{o} \operatorname{Re}_{o}^{P} \operatorname{Pr}_{o}^{0.333}\left(\frac{\mu}{\mu_{w}}\right)_{o}^{0.14}
\end{aligned}
$$


constant at about 3000,4500 and 7000 . These results were plotted on a x-y coordinate system, from which the $C_{i}$ and $C_{o}$ multipliers were calculated for each individual experiment. The average value from the three experiments was used to determine the two multipliers.

The value of $C_{i}$ was 0.01923 which corresponds well with the value of 0.027 of the Sieder-Tate equation. The value of $C_{o}$ (the other multiplier) was 0.0726 and the value of $P$ was 0.8 . With these values and Eq. (1) the theoretical heat transfer was calculated and compared to measurements. The average error between the theoretical and experimental results was $2.9 \%$ with a standard deviation of $1.9 \%$.

When angled spiralling tape is considered the heat transfer correlation for the inner tube given in Eq. (3) would still be valid. Therefore similar experiments as before were done for each of the three heat exchangers with angled spiralling tapes. Each one was considered with flow against the curvature of the tape and along the curvature of the tape as shown in Fig. 3.
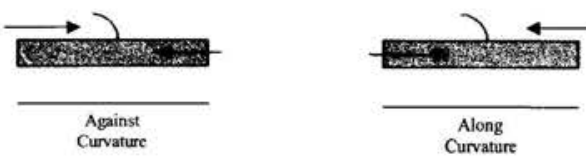

Figure 3: Flow in the Annulus Against and Along the Curvature of the Tape.

During the experiments the flow rate through the inner tube was kept constant at a Reynolds number of approximately 16000 . The flow rate in the annulus was varied from a Reynolds number of 3000 to approximately 25000 . From the temperature readings the heat transfer, logarithmic mean temperature difference and overall heat transfer coefficient could be determined. With the heat transfer coefficient of the inner tube known from Eq. (3), the heat transfer coefficient in the annulus could be determined.

\section{Pressure Drop}

The pressure drops were determined from the differences of the manometers from which the pressure drop coefficient was determined from $C P=\Delta p /\left(1 / 2 \rho v^{2}\right)$. For verification purposes the pressure drop coefficients for the inner tube and annulus were also determined analytically. The friction factor needed to determine the pressure drop coefficient was determined from the Swamee and Jain equation [13] for the inner tube. For the annulus the Petukhov equation [13] was used to calculate the friction factor. The Petukhov equation was based on the hydraulic diameter.

\section{RESULTS}

In Fig. 4 the heat transfer results for the three experimental set-ups are plotted against the Reynolds number. The Nusselt number results for the plain tube-in-tube heat exchanger are also shown for comparison purposes (Eq. (4)).

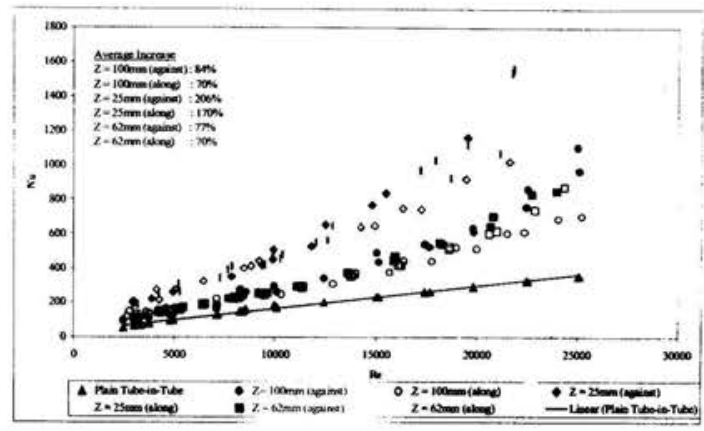

Figure 4: Nusselt Number Comparison for Flow Against and Along the Curvature of the Tape.

Since all the experiments were conducted for turbulent flow, the results lie in a Reynolds number range of 3000 upwards. The experimental and theoretical results obtained from Eq. (4), for the plain tube-in-tube heat exchanger correlate well with each other. These results form an almost linear tendency, since the Nusselt number is directly proportionate to $R e^{0.8}$. However, the results for the heat exchangers with angled spiralling tape inserts tend more to a parabolic correlation.

An average increase of $206 \%$ in the Nusselt numbers was noted from a plain tube-in-tube heat exchanger to a heat exchanger with a twist ratio of $0.731(Z=25 \mathrm{~mm})$ and flow against the curvature of the tape. The heat exchangers with a twist ratio of $1.799(Z=62 \mathrm{~mm})$ and $2.878(Z=100 \mathrm{~mm})$ produced very similar results. The average increase in the Nusselt number for these two set-ups was in the order of $80 \%$ for flow against the curvature of the tape and $70 \%$ for flow along the curvature.

Illustrated in Fig. 5 the enhancement factor is plotted against the Reynolds number for all the experiments conducted. The enhancement factor was calculated as the ratio of the measured Nusselt number for a tape insert to the Nusselt number of a plain tube heat exchanger. If necessary the Nusselt number for the plain tube-in-tube heat exchanger was determined with linear interpolation, if a value was not available at the Reynolds number where measurements were taken for the configuration with tape inserts.

The enhancement factor decreased slightly to a minimum value for each experiment. From a Reynolds number of about 6000 the enhancement factor increased with an increase in the Reynolds number. The highest increase in the enhancement factor was produced for the experimental set-up with a twist ratio of $0.731(Z=25 \mathrm{~mm})$ and flow against the curvature of the tape. The enhancement factor decreased from just below 3 to about 2.5 , before increasing to about 4.5 . 


$$
N u=0.0726 \operatorname{Re}^{0.8} \operatorname{Pr}^{0.333}\left(\frac{\mu}{\mu_{*}}\right)^{0.14}\left[f_{1}(y) \operatorname{Re}^{2}+f_{2}(y) \operatorname{Re}+f_{3}(y)\right]
$$

where for flow against the curvature of the tape:

$$
\begin{aligned}
& f_{1}(y)=2.256 \times 10^{-9} y^{2}-10.989 \times 10^{-9} y+16.03 \times 10^{-9} \\
& f_{2}(y)=-21.04 \times 10^{-6} y^{2}+125.27 \times 10^{-6} y-211.33 \times 10^{-6} \\
& f_{3}(y)=0.449 y^{2}-2.329 y+4.503
\end{aligned}
$$

and for flow along the curvature of the tape, the functions are given by:

$$
\begin{aligned}
& f_{1}(y)=-0.3969 \times 10^{-9} y^{2}+1.233 \times 10^{-9} y+3.369 \times 10^{-9} \\
& f_{2}(y)=4.866 \times 10^{-6} y^{2}-26.27 \times 10^{-6} y-54.17 \times 10^{-6} \\
& f_{3}(y)=0.449 y^{2}-1.969 y+4.021
\end{aligned}
$$

The comparison of the experimental Nusselt numbers and the Nusselt numbers obtained from Eq. (5) for flow against and along the curvature of the tape is illustrated in Fig. 8.

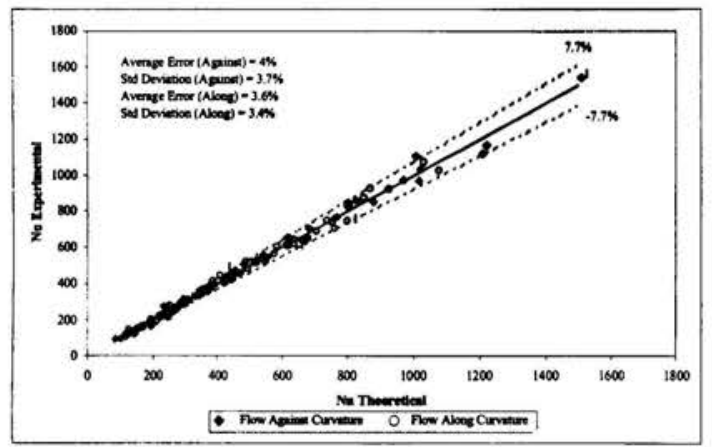

Figure 5: Error Calculation for the Nusselt Number Comparison for Flow Against and Along the Curvature of the Tape.

It was determined that the correlation results in an average error of $4 \%$ with a standard deviation of $3.7 \%$ for flow against the curvature of the tape. In the case of flow along the curvature of the tape an average error of $3.6 \%$ was determined with a standard deviation of $3.4 \%$.

\section{Friction Factor}

Equation (14) depicts the final friction factor correlation developed for tube-in-tube heat exchangers with angled spiralling tape inserts.

$$
f=g_{1}(y) \operatorname{Re}^{g_{2}(y)}
$$

where for flow against the curvature of the tape:

$$
\begin{aligned}
& g_{1}(y)=0.3618 y^{2}-1.047 y+0.9186 \\
& g_{2}(y)=-0.0669 y^{2}+0.1656 y-0.2282
\end{aligned}
$$

and for flow along the curvature of the tape, the functions are given by:

$$
\begin{aligned}
& g_{1}(y)=0.6283 y^{2}-1.6519 y+1.1939 \\
& g_{2}(y)=-0.0797 y^{2}+0.1814 y-0.2392
\end{aligned}
$$

The comparison of the experimental friction factors and the friction factors obtained from Eq. (12) for flow against the curvature of the tape is illustrated in Fig. 9.

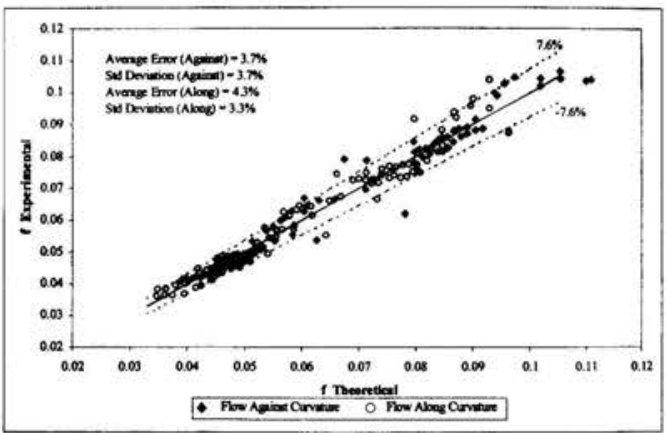

Figure 6: Error Calculation for the Friction Factor Comparison for Flow Against and Along the Curvature of the Tape.

The correlation results in an average error of $3.7 \%$ with a standard deviation of $3.7 \%$ for flow against the curvature of the tape. In the case of flow along the curvature of the tape an average error of $4.3 \%$ was determined with a standard deviation of $3.3 \%$.

\section{CONCLUSION}

To study the heat transfer and pressure drop characteristics of angled spiralling tape augmentation devices, four experimental set-ups were constructed. Three tube-in-tube heat exchangers were manufactured with angled spiralling tape in the annulus with a pitch of $25 \mathrm{~mm}, 62 \mathrm{~mm}$ and $100 \mathrm{~mm}$. The fourth experimental set-up was a plain tube-in-tube heat exchanger to be used for comparison purposes.

It was determined that the heat exchanger with a pitch of $25 \mathrm{~mm}$ and with flow against the curvature of the tape resulted in the highest increase in the Nusselt number, with an average increase of $206 \%$. This heat exchanger also had the best enhancement factor increase. As penalty this heat exchanger also had the highest increase in the pressure drop, with an average increase of $203 \%$. The heat exchanger with the lowest increase in the pressure drop, was for a pitch of $100 \mathrm{~mm}$ and 
flow along the curvature of the tape. The average increase was $58 \%$.

The experimental set-ups with a pitch of $62 \mathrm{~mm}$ and $100 \mathrm{~mm}$ correlated well with each other for both the heat transfer and pressure drop results. A possible explanation for this correlation is that the performance follows a hyperbolic tendency as the pitch increases. From the results obtained it is assumed that the best heat transfer performance is obtained at the smallest pitch of the tape. The opposite is assumed for the best pressure drop performance, where the lowest increase should be obtained at the highest pitch of the tape.

This heat exchanger with a pitch of $25 \mathrm{~mm}$ resulted in the highest increase in the Nusselt numbers over a plain tube-intube heat exchanger. Unfortunately, an increase in the pressure drop coefficients close to the Nusselt number increase was also obtained. However, a higher increase in the enhancement factor was achieved than the increase in the pressure factor. This was not the case for the other experimental set-ups, thus, it is concluded that the heat exchanger with a pitch of $25 \mathrm{~mm}$ produced the optimum performance.

With the experimental results concluded, a correlation to predict the heat transfer coefficient and friction factor for a heat exchanger with angled spiralling tape inserts was developed. Both the correlations developed resulted in average errors below $8 \%$ for flow against and along the curvature of the tape. Since the experimental results correlated well with the values predicted by the equations, it is concluded that the correlations are accurate enough to predict the heat transfer and pressure drop characteristics for a heat exchanger with angled spiralling tape inserted into the annulus.

\section{ACKNOWLEDGEMENTS}

The work in this paper is a summary of the work done by the first author under supervision of the second author for a Master's degree in Engineering.

\section{REFERENCES}

[1] Bergles, A. E., November 1988, "Some Perspectives on Enhanced Heat Transfer - Second-Generation Heat Transfer Technology," ASME Journal of Heat Transfer, Vol. 110,pp. 1082-1096.

[2] Meyer, J. P., Bukasa, J. M. and Kebonte, S., 2000, "Average Boiling and Condensation Heat Transfer Coefficients of the Zeotropic Refrigerant Mixture R22/R142b in a Coaxial Tube-in-Tube Heat Exchanger," Journal of Heat Transfer, Vol. 122, No. 1, pp. 186-188.

[3] Liebenberg, L., Bergles, A. E. and Meyer, J. P., 2000, “A Review of Refrigerant Condensation in Horizontal MicroFin Tubes," Proceedings of the ASME Advanced Energy Systems Divisions, 2000 ASME International Mechanical Engineering Congress and Exposition, Orlando, Florida, USA, AES-Vol. 40, pp. 155-168.
[4] Van der Vyver, S. and Meyer, J. P., 1997, "Heat Transfer Augmentation in the Annulus of a Heat Exchanger Consisting of a Round Tube Inside a Twisted Square Tube," R \& D Journal, Vol. 13, No. 3, pp. 77-82.

[5] Herman, H. and Meyer, J.P., 1998, "Heat Transfer Augmentation of a Spiralled Tube Inside the Annulus of a Tube-in-Tube Heat Exchanger," South Africa's $10^{\text {th }}$ International Air-Conditioning, Refrigeration \& Ventilation Congress, 8-10 March, Midrand, South Africa.

[6] Coetzee, S., Da Veiga, W. R. and Meyer, J. P., 2000, "Enhancement of R22 Condensation Employing Spiralled Wires in the Annulus of a Tube-in-Tube Heat Exchanger, for Use in Hot-Water Heat Pumps," South Africa's $10^{\text {th }}$ International Air-Conditioning, Refrigeration \& Ventilation Congress, 8-10 March, Midrand, South Africa.

[7] Dirker, J., Van der Hoek, L. and Meyer, J. P., 2000, "Heat Transfer Augmentation with Spiralled Wires During Condensation in the Annulus of a Coiled Tube-in-Tube Heat Exchanger for Hot-Water Heat Pumps," $3^{\text {rd }}$ European Thermal Sciences Conference, 10-13 September, Heidelberg, Germany, Vol. 2, pp. 1187-1192.

[8] Maxwell, B. H., 2000, "Condensation of R22 During Heat Transfer Augmentation With Spiralled Wires in the Annulus of a Tube-in-Tube Heat Exchanger for Hot Water Heat Pumps," Final-Year Project, Rand Afrikaans University, Johannesburg, South Africa.

[9] Ferreira, J., 2000., "Heat Transfer Augmentation During the Condensation of R22 With $1.6 \mathrm{~mm}$ Spiralled Wires in the Annulus of a Counterflow Tube-in-Tube Heat Exchanger for Hot-Water Heat Pumps," Final-Year Project, Rand Afrikaans University, Johannesburg, South Africa.

[10] Krüger, E., 2000, "Comparison Between CFD Analysis and Experimental Work on Heat Exchangers," Master's Dissertation, Rand Afrikaans University, Johannesburg, South Africa.

[11] Meyer, J. P. and Coetzee, H., 1999, "Tube-in-Tube Heat Exchanger with Enhanced Heat Transfer," Patent no. 99/5561 (South Africa).

[12] Briggs, D. E. and Young, E. H., 1969, "Modified Wilson Plot Techniques for Obtaining Heat Transfer Correlations for Shell and Tube Heat Exchangers," Chem. Eng. Prog. Symp., Ser. 92, Vol. 65, pp. 35-45.

[13] Incropera, F. P. and DeWitt D. P., 1996, "Introduction to Heat Transfer," Third Edition, John Wiley \& Sons.

[14] Coetzee, H., 2001, "Heat Transfer and Pressure Drop Characteristics of Angled Spiralling Tape Inserts in a Heat Exchanger Annulus," Master's Dissertation, Rand Afrikaans University, Johannesburg, South Africa. 